\title{
THE EFFECT OF 5-FU AND RUXOLITINIB ON MITOCHONDRIAL APOPTOSIS IN GLIOBLASTOMA U87 CELL LINE
}

\author{
Gonca Aksu, Oğuzhan Doğanlar², Zeynep Banu Doğanlar² \\ ${ }^{1}$ Trakya University School of Medicine, Edirne, TURKEY \\ ${ }^{2}$ Department of Medical Biology, Trakya University School of Medicine, Edirne, TURKEY
}

\begin{abstract}
Aims: The aim of this study is to carry out the effect of 5-Fluorouracil alone or combined with Ruxolitinib on both apoptosis and JAK/STAT pathway in U87 glioblastoma cells. Methods: We used U87 glioblastoma cell lines as the human brain cancer cells. We treated the cells with 5-Fluorouracil $(3.125 \mu \mathrm{M}-400 \mu \mathrm{M})$ alone and with a combination of Ruxolitinib $(100 \mu \mathrm{M}$ or $400 \mu \mathrm{M}$ of Ruxolitinib with 3.125-25 $\mu \mathrm{M}$ 5-Fluorouracil), and performed the MTT test for calculating IC50 value. Molecular fluorescence staining was performed with Hoechst and acridine orange/ethidium bromide probes. The alteration in mitochondrial apoptosis and JAK/STAT pathways to drug treatment was analyzed by the qRT-PCR assay. Results: Decrease in cell viability was more prominent in U87 cells treated with a combination of 5-Fluorouracil and Ruxolitinib compared to those treated with 5-Fluorouracil alone. In gene expression analysis, apoptosis signals were observed in cells treated with 5-Fluorouracil alone and 5-Fluorouracil+Ruxolitinib treatment. Conclusion: Treatment with 5-Fluorouracil alone and 5-Fluorouracil+Ruxolitinib combination increased apoptosis in U87 glioblastoma cells. However, it is difficult to mention an evident difference between treatments. Therefore, further studies are needed. Keywords: 5-Fluorouracil, Ruxolitinib, glioblastoma, apoptosis, JAK/STAT pathway
\end{abstract}

\section{INTRODUCTION}

Glioblastoma multiforme (GBM), one of the aggressive, angiogenic and invasive brain tumors with poor prognosis (5-year survival rate is $4-5 \%$ ), is the most common malignant primary brain tumor $(1,2)$. About $5 \%$ of patients with glioma are associated with hereditary syndromes, while other patients represent sporadic cases. Accumulation of genetic damage and abnormal growth factor signaling pathways leading to malignant transformation play an important role in the pathogenesis of glioma (3). In 2016, GBM was classified by World Health Organization as Isocitrate Dehydrogenase (IDH)-wild type, IDH-mutant, and otherwise specified. The type of epithelioid glioblastoma defined in 2016 is mostly found in IDH-wild type glioblastoma, giant cell glioblastoma, and gliosarcoma (2).

5-Fluorouracil (5-FU) has been in use since 1957. It has been used as an intravenous drug for various types of cancer including basal cell carcinoma, colorectal cancer, breast cancer, pancreatic cancer, gastric adenocarcinoma, head, and neck squamous cell carcinoma. Additionally, it is given locally for the treatment of corneal squamous cell carcinoma and actinic keratosis. 5-FU can be used at the operation site to prevent conjunctival scarring, and intraoperatively or postoperatively in glaucoma surgery (4). Uracil is required for nucleic acid synthesis, which is essential for tumor growth. While 5-FU is an analog of naturally occurring pyrimidine uracil and is metabolized by the same metabolic pathways as uracil, un-metabolized 5-FU cannot bind to the DNA structure, which is the main target site in the mammalian host and tumor cells. However, the cytotoxic effect of 5-FU is only against nucleotides after anabolism in actively proliferating cells (5). In the $S$ phase of the cell cycle, it forms a complex with the enzyme thymidylate synthetase, blocks DNA synthesis and stops the cell cycle. It can also inhibit RNA synthesis by forming misconfigured ribonucleic acids (6). 
Ruxolitinib (Ruxo), which is also known as INC424 or INCB18424, is a potent and selective inhibitor of Janus Kinase 1 (JAK1) and Janus Kinase 2 (JAK2). JAK1 and JAK2 are non-receptor tyrosine kinases, which are important components of pathways leading to the production and secretion of inflammatory cytokines and hematological growth factors. Inhibition of JAK1 and JAK2 may cause antiproliferative and antiapoptotic effects. Ruxolitinib causes Janus Kinase mutations. Its main effect is inhibition of cell division by preventing JAK to phosphorylate the signal transducer and activator of transcription (STAT) to induce apoptosis. Ruxo is the first agent used to treat myelofibrosis, which is a disease characterized by progressive bone marrow fibrosis, inadequate hematopoiesis, cytopenia, anemia, and splenomegaly and affecting the older age group (>60 years) (7). It has also been shown that it decreases the symptoms of polycythemia vera disease, by reducing the size of the spleen and circulating cytokine levels (8). Additionally, Ruxo inhibits glioblastoma invasion and angiogenesis (9).

5-Fluorouracil blocks DNA synthesis and stops the cell cycle. It can also inhibit RNA synthesis by forming misconfigured ribonucleic acids. Ruxo causes Janus kinase mutations. Inhibition of JAK1 and JAK2 may cause antiproliferative and antiapoptotic effects. Therefore, we aimed to carry out the effect of 5-FU alone or combined with Ruxolitinib on both apoptosis and JAK/ STAT pathways in U87 glioblastoma cells.

\section{MATERIAL AND METHODS}

\section{CELLS AND REAGENTS}

U87 human brain cancer cell line was purchased from American Type Culture Collection (ATCC). It was cultured in Dulbecco's Modified Eagle Medium: F-12 (DMEM: F-12, ATCC 30-2006TM) supplemented with heat-inactivated 10\% fetal bovine serum (Gibco Life Technologies, USA), 2 mM glutamine (Gibco-Life Technologies, USA), and 1\% penicillin/streptomycin (Invitrogen, Life Technologies, USA). The U87 cell culture was maintained at $37^{\circ} \mathrm{C}$ and $5 \% \mathrm{CO} 2$ in the cell culture laboratory under sterile conditions.

5-Fluorouracil sodium hydroxide was obtained from the chemotherapy unit (Fluorouracil-GRYVR: 1000 $\mathrm{mg} / 20 \mathrm{ml}$, Teva GmbH, Germany) and Ruxolitinib Phosphate was purchased from Santa Cruz Biotechnology (Chem Cruz, Sc-396768A, USA). MTT (3-(4,5-Dimethylthiazol-2-yl)-2,5-Diphenyltetrazolium Bromide), ultrapure DNase/RNase-free water, NucBlue ${ }^{\mathrm{Tm}}$ Live
ReadyProbes $^{\mathrm{Ts}}$ Reagent, the PureLink ${ }^{\circledast}$ RNA Mini Kit, a High Capacity complementary DNA (cDNA) Reverse Transcription Kit, and SYBR ${ }^{\odot}$ Select Master Mix were purchased from Thermo Fisher Scientific.

\section{CELL PROLIFERATION ASSAY (MTT)}

Cell viability and proliferation were determined by MTT assay. U87 cells were seeded in a 96-well plate and incubated for 12h in DMEM: F12 medium to ensure cell attachment. The cells were treated with 5-Fu alone and combined with Ruxo. For 5-Fu alone treatments, cells were treated with $400 \mu \mathrm{M}$ to $3.125 \mu \mathrm{M}$ with the 10 -fold dilutions. For combined treatments, $100 \mu \mathrm{M}$ or $400 \mu \mathrm{M}$ of Ruxo and 25-3.125 $\mu \mathrm{M}$ of 5-FU were used. Treated cells were incubated for $24 \mathrm{~h}$. At the end of this period, $20 \mu \mathrm{L}$ MTT solution $(5 \mathrm{mg} / \mathrm{mL})$ was added to each well and the cells were incubated for $4 \mathrm{~h}$ at $37^{\circ} \mathrm{C}$. Then 180 $\mu \mathrm{L}$ dimethyl sulfoxide (DMSO) was added to the cells and the cells were analyzed at $492 \mathrm{~nm}$ with a microplate reader (Multiscan Go, Thermo Scientific, USA).

\section{MOLECULAR FLUORESCENT STAINING}

Cells were seeded into six-well plates with a density of $5 \times 104$ cells/well. After attachment of the cells, 5 -FU and 5-FU+Ruxo treatments were performed. After the incubation period, cells were labeled with four drops of NucBlue ${ }^{\circledast}$ Live ReadyProbes ${ }^{\circledast}$ Reagent $(40.6 \mu \mathrm{M}$ Hoechst 33342, Thermo Scientific, USA), and ethidium bromide and acridine orange solution $(10 \mu \mathrm{g} / \mathrm{mL} \mathrm{AO}$ and $100 \mu \mathrm{g} / \mathrm{mL} \mathrm{EB}$ ) for $30 \mathrm{~min}$ at $37^{\circ} \mathrm{C}$. AO stains both live and dead cells, EB stains only dead cells that have lost their membrane integrity. NucBlue ${ }^{\circledast}$ Live Ready Probes were used for staining the nuclei. Then, cells were rinsed with phosphate-buffered saline, and a fresh medium was added. Images were acquired at $\times 40$ magnification on a Zeiss Axio Vert. A1 fluorescence microscope with a DAPI filter for NucBlue ${ }^{\varpi}$, and FITC/Texas Red filter for EB-AO.

\section{ISOLATION OF TOTAL RNA, cDNA SYNTHE- SIS, AND QUANTITATIVE REAL-TIME PCR (qRT-PCR) ANALYSIS}

Total RNA was isolated from three $25-\mathrm{cm}^{2}$-tissue culture plates of each experimental group using the PureLink RNA Mini Kit (Life Technologies) according to the manufacturer's instructions. The extracted RNA concentrations were measured by the OPTIZEN NanoQ micro-volume photometer. The synthesis of the first strand of complementary DNA (cDNA) was performed 
using a High-Capacity cDNA Reverse Transcription Kit (Life Technologies). cDNA synthesis was performed using the thermal cycler Applied Biosystems ProFlex PCR System (step 1, $25^{\circ} \mathrm{C}-10 \mathrm{~min}$; step 2, $37^{\circ} \mathrm{C}-120$ min; step 3, $85^{\circ} \mathrm{C}-5 \mathrm{~min}$ ). The cDNA was stored at $-20{ }^{\circ} \mathrm{C}$ for subsequent steps of the analysis. Expression levels of genes that involve in apoptosis pathway (tumor suppressor (P53), B-cell lymphoma 2 (BCL2), BCL2 associated X protein (BAX), cytochrome complex (Cyt-C), caspase 3 and caspase 8), JAK1, JAK2, STAT3, Interleukin 6 (IL-6) and $\beta$-actin were analyzed by qRT-PCR using the SYBR Select Master Mix (Life Technologies) on Quant Studio 5 Real-Time PCR system. qRT-PCR conditions and Primer pairs are shown in Table 1. Relative fold changes were calculated by the 2(-Delta Delta $\mathrm{C}(\mathrm{T})$ ) method and all data were normalized with control expression value that was set up as 1 .

\section{STATISTICAL ANALYSIS}

The differences in the gene expressions were compared using the independent sample T-test and analysis of variance (ANOVA) with Tukey, HSD separation of means test using the IBM SPSS version 20 software at a significance level of $\mathrm{p} \leq 0.05$.

Table 1: Primer sequences and qRT-PCR conditions.

\begin{tabular}{|c|c|c|c|c|c|}
\hline Primer name & & & Primer sequence & & $q R T-P C R$ conditions \\
\hline \multirow[t]{2}{*}{$P 53$} & $\mathrm{~F}$ & $5^{\prime}$ & CACGAGCGCTGCTCAGATAGC & $3^{\prime}$ & \\
\hline & $\mathrm{R}$ & $5^{\prime}$ & ACAGGCACAAACACGCACAAA & $3^{\prime}$ & \\
\hline \multirow[t]{2}{*}{$B C L 2$} & $\mathrm{~F}$ & $5^{\prime}$ & ATGTGTGTGTGGAGAGCGTCAA & $3^{\prime}$ & \\
\hline & $\mathrm{R}$ & $5^{\prime}$ & ACAGTTCCACAAAGGCATCC & $3^{\prime}$ & \\
\hline \multirow[t]{2}{*}{$B A X$} & $\mathrm{~F}$ & $5^{\prime}$ & TTCATCCAGGATCGAGCAGA & $3^{\prime}$ & \\
\hline & $\mathrm{R}$ & $5^{\prime}$ & GCAAAGTAGAAGGCAACG & $3^{\prime}$ & \\
\hline \multirow[t]{2}{*}{ Cyt-C } & $\mathrm{F}$ & $5^{\prime}$ & AGTGGCTAGAGTGGTCATTCATTTACA & $3^{\prime}$ & \\
\hline & $\mathrm{R}$ & $5^{\prime}$ & TCATGATCTGAATTCTGGTGTATGAGA & $3^{\prime}$ & \\
\hline \multirow[t]{2}{*}{ CASP3 } & $\mathrm{F}$ & $5^{\prime}$ & GGTATTGAGACAGACAGTGG & $3^{\prime}$ & \\
\hline & $\mathrm{R}$ & $5^{\prime}$ & CATGGGATCTGTTTCTTTGC & $3^{\prime}$ & \\
\hline \multirow[t]{2}{*}{ CASP8 } & $\mathrm{F}$ & $5^{\prime}$ & AGAGTCTGTGCCCAAATCAAC & $3^{\prime}$ & of $2 \mathrm{~min}$ at $50^{\circ} \mathrm{C}$ and \\
\hline & $\mathrm{R}$ & $5^{\prime}$ & GCTGCTTCTCTCTTTGCTGAA & $3^{\prime}$ & 10 min at $95^{\circ} \mathrm{C}$ followed by \\
\hline \multirow[t]{2}{*}{$J A K 1$} & $\mathrm{~F}$ & $5^{\prime}$ & ACAATTGGCATTCATTTTCCTG & $3^{\prime}$ & 42 cycles of denaturation at \\
\hline & $\mathrm{R}$ & $5^{\prime}$ & CCTGGGCCCAAACTTCCTA & $3^{\prime}$ & $95^{\circ} \mathrm{C}$ for $15 \mathrm{~s}$, annealing and \\
\hline \multirow[t]{2}{*}{ JAK2 } & $\mathrm{F}$ & $5^{\prime}$ & CAGTGGTCAAGAGGGAAACA & $3^{\prime}$ & extension at $60^{\circ} \mathrm{C}$ for $1 \mathrm{~min}$ \\
\hline & $\mathrm{R}$ & $5^{\prime}$ & TGTCTGAGCGAACAGTTTCC & $3^{\prime}$ & \\
\hline \multirow[t]{2}{*}{ STAT3 } & $\mathrm{F}$ & $5^{\prime}$ & GGAGGAGTTGCAGCAAAAAG & $3^{\prime}$ & \\
\hline & $\mathrm{R}$ & $5^{\prime}$ & TGTGTTTGTGCCCAGAATGT & $3^{\prime}$ & \\
\hline \multirow[t]{2}{*}{$I L-6$} & $\mathrm{~F}$ & $5^{\prime}$ & ATGAACTCCTTCTCCACAAG & $3^{\prime}$ & \\
\hline & $\mathrm{R}$ & $5^{\prime}$ & AGAGCCCTCAGGCTGGACTG & $3^{\prime}$ & \\
\hline \multirow[t]{2}{*}{ GAPDH } & $\mathrm{F}$ & $5^{\prime}$ & TTGGTATCGTGGAAGGACTCA & $3^{\prime}$ & \\
\hline & $\mathrm{R}$ & $5^{\prime}$ & TGTCATCATATTTGGCAGGTTT & $3^{\prime}$ & \\
\hline \multirow[t]{2}{*}{$\beta$-ACTIN } & $\mathrm{F}$ & $5^{\prime}$ & CCTCTGAACCCTAAGGCCAAC & $3^{\prime}$ & \\
\hline & $\mathrm{R}$ & $5^{\prime}$ & TGCCACAGGATTCCATACCC & $3^{\prime}$ & \\
\hline
\end{tabular}




\section{RESULTS}

After incubation of U87 cells with different concentrations of 5-FU and 5-FU+Ruxo for 24 hours, cell viability was determined by MTT assay. As seen in Figure 1 , the dose-dependent inhibition of cell viability was determined both 5-FU alone and 5-FU+Ruxo treatment. The viability of control cells was designated as $100 \%$, and the others were expressed as percent compared to the control (Figure 1). The IC50 value was calculated as $118 \mu \mathrm{M}$ for 5-FU alone and $50 \mu \mathrm{M} 5-\mathrm{FU}+100$ nM Ruxo using Probit analysis.

On the other hand, the 5-FU and 5-FU+Ruxo treatment caused a 15.1 and 3.4-fold increase in BAX gene expression, the BAX/BCL2 ratio as indicative of apoptosis was determined as 9.68 and 1.46 at 5 -FU and 5-FU+Ruxo, respectively. While P53 and caspase-3 gene expressions showed no significant changes at both 5-FU alone and combined with Ruxo, caspase 8 was significantly upregulated by 5 -FU alone treatment (69.97-fold) (Figure 2).

For visualization of the apoptotic effect of $5-\mathrm{FU}$ alone or in combination with Ruxo, we used both Hoechst 33342 and the EB-AO dual staining. As seen in Figure 3, cell morphologies were different between control, 5-FU, and 5-FU+Ruxo treatments. Additionally, cells treated with 5-FU caused more apoptosis and showed higher blue fluorescence due to fragmented nucleus and apoptotic body formation in Hoechst 33342 staining. Acridine Orange dye penetrates normal cells and early apoptotic cells (intact membrane integrity) and emits green fluorescence when bound to DNA. U87 cells treated with 5-FU and 5-FU+Ruxo have been observed to emit less green fluorescence when stained with $\mathrm{AO}$ and undergo more apoptosis compared to control. It was observed that viability is less especially in 5 -FU+Ruxo treatment. EB enters cells with membrane damage, such as late apoptotic and dead cells, and emits orange-red fluorescence when bound to dense DNA fragments and apoptotic bodies. When U87 cells were treated with 5-FU and 5-FU+Ruxo, they were stained with $\mathrm{EB}$, more intense apoptotic bodies were observed compared to the control group (Figure 3).

In this study, we investigated the effect of 5-Fu and 5-FU+Ruxo treatment on IL 6 /JAK1-2/ STAT3 axis of JAK/STAT pathway using gene expression levels in control and experimental groups of U87 cells. Our results showed that there was no significant change in IL6 and STAT3 gene expression levels in the control and administration groups. While JAK1 (16.2-fold) and JAK2 (3.3- fold) gene expressions were upregulated in
5-FU administration, the inclusion of the specific JAK inhibitor Ruxo in the treatment decreased the gene expression levels of both genes. However, these increases and decreases were statistically significant only for JAK2 (Figure 4).

\section{DISCUSSION}

In previous studies, 5-FU has been shown to be curative in the treatment of non-invasive basal cell carcinomas and has a positive activity in the treatment of gastrointestinal, ovarian, and breast cancers (5). Delen et al. (9) reported that Ruxo, used against myeloproliferative neoplasms in the clinic, has been shown to significantly inhibit tumor invasion in GBM cells. However, the effect of the combination of 5-FU and Ruxo on GBM cells has not been studied. In this study, we examined the apoptotic effects of 5-FU and 5-FU+Ruxo combination on U87 cells. According to the study, 5-FU and the combination of 5-FU+Ruxo decreased the proliferation of U87 cells. Bcl-2 gene family consists of antiapoptotic and proapoptotic members. While Bcl-2 suppressing apoptosis, another member of the family, BAX, speeds up cell death. BAX/Bcl-2 ratio plays an important role in cell apoptosis. In addition to the members of the Bcl-2 family, the p53 protein regulates cellular functions such as DNA synthesis, DNA repair, cell cycle arrest, and apoptosis (10). A significant increase in p53 expression was observed in colorectal adenocarcinoma cells treated with 5-FU in a study performed by Erdoğan et al. (11). Furthermore, it was observed that $\mathrm{Bcl}-2$ expression decreased significantly in these cells and there was a significant increase in Bax gene expression (11). In our study, change in p53 expression was found statistically insignificant in U87 cells treated with 5-FU, and a combination of 5-FU+Ruxo. Bax expressions increased when 5-FU alone was used, while Bcl-2 expression increased in 5-FU+Ruxo combination therapy. On the other hand, the increased rate of BAX/ Bcl-2 expression in U87 cells treated with 5-FU+Ruxo combination is lower than 5 -FU alone, meaning that the apoptotic effect of only $5-\mathrm{FU}$ is more evident.

When moderately and poorly differentiated prostate cancer samples were compared with healthy tissues, a decreased caspase 3 expression was observed (12). Caspase-8 expression loss was observed in high-grade small cell lung cancer, neuroendocrine lung cancer, and pediatric neuroblastoma $(13,14)$. In our study, a statistically significant increase was observed in caspase- 8 expression in U87 cells treated with only 5-FU. 

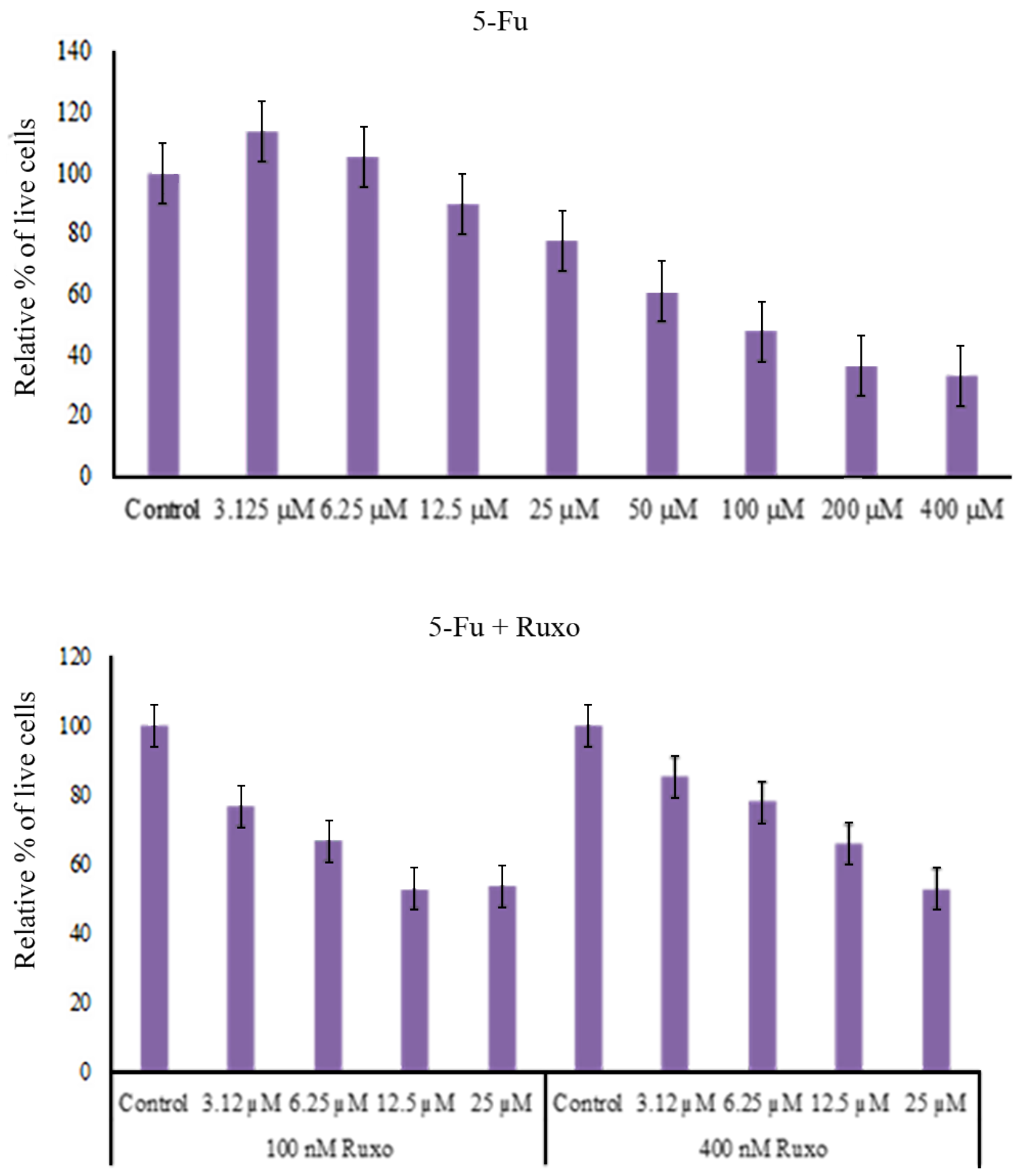

Figure 1: The effect of 5-FU and 5-FU+Ruxo treatment for 24 hours on cell viability in U87. ( $n=6$. Data \% viability mean \pm standard error. 5-Fu:5-Fluorouracil Ruxo: Ruxolitinib.) 

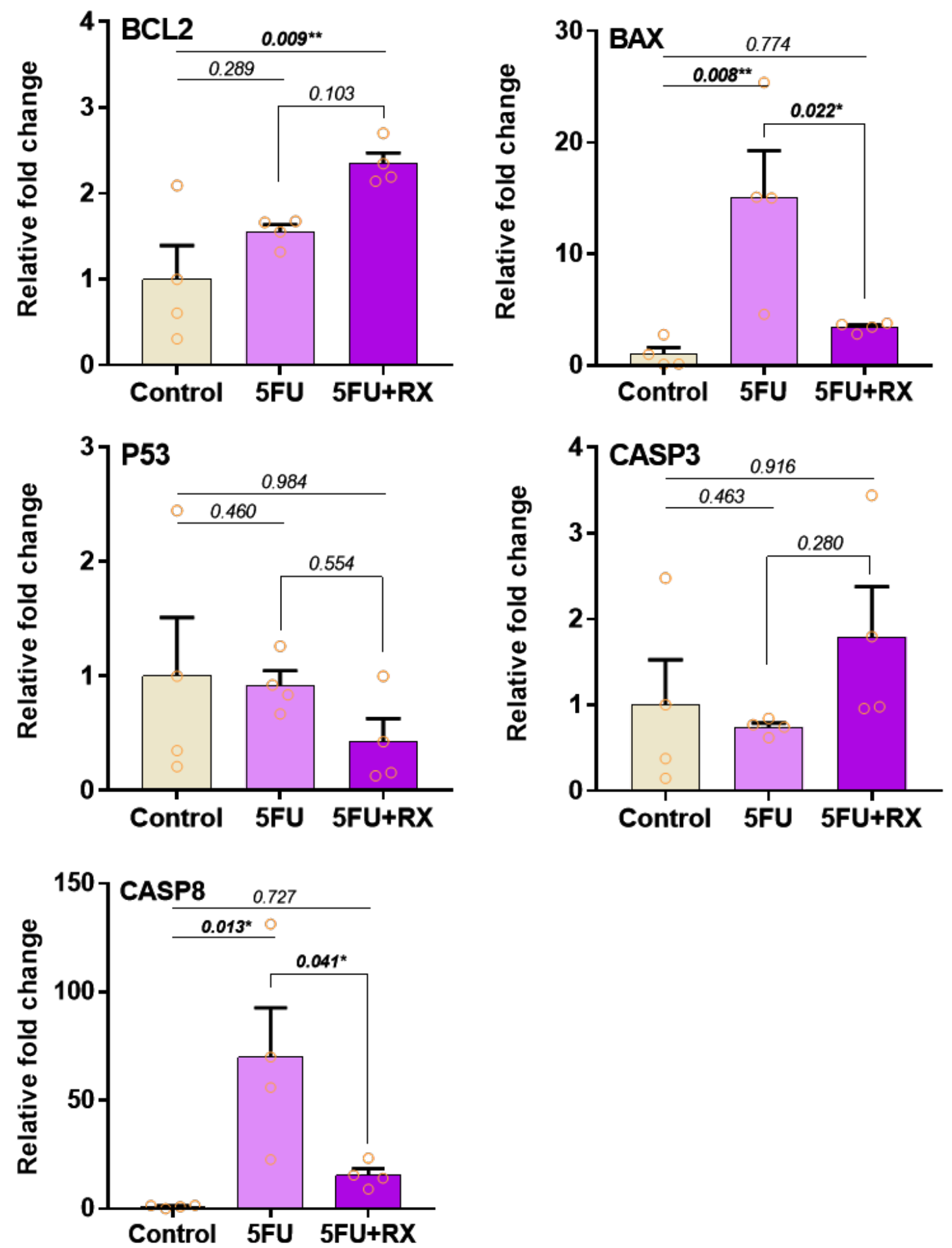

Figure 2: Relative fold change qRT-PCR analysis of apoptosis pathway genes in IC50 doses of 5-FU and 5-FU+Ruxo exposed U87 cell line. (All data were normalized with $\beta$-actin expression and given as relative to control (control $=1)$. Values expressed as mean \pm standard error $(n=4) .{ }^{*}$ Indicates significantly different values, one-way ANOVA, Tukey HSD test : $p \leq 0.05,{ }^{* *} p \leq 0.01$.) 


\section{(TMSJ}
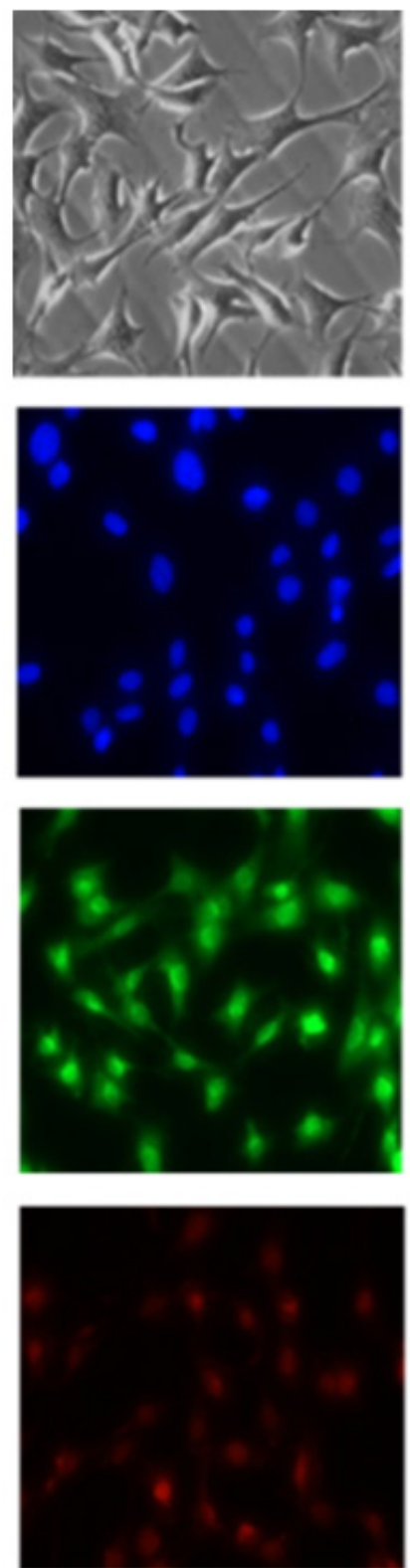

Control
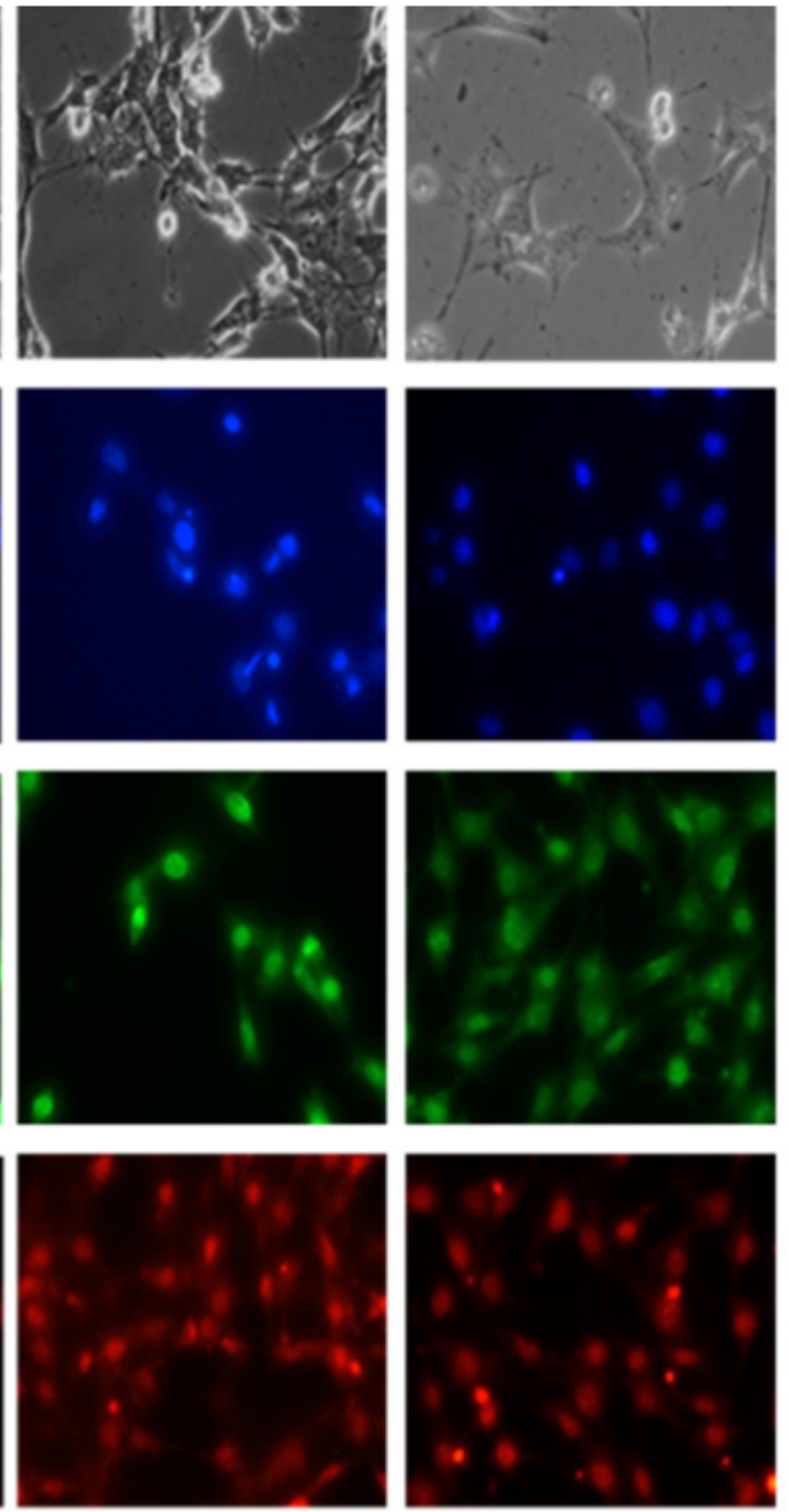

5-Fu

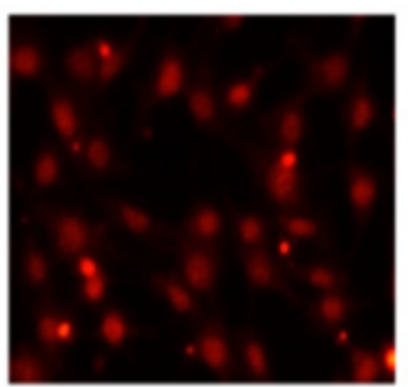

5-Fu+Ruxo
Bright Field

Hoechst 33342 (DAPI Filter)

AO/EB (FITC Filter)

AO/EB (Texas Red Filter)

Figure 3: Bright field and Fluorescence microscopic images of U87 cells treated with 5-FU alone or in combination with Ruxo at IC50 dose after incubation for 24 hours of the U87 cell line. 

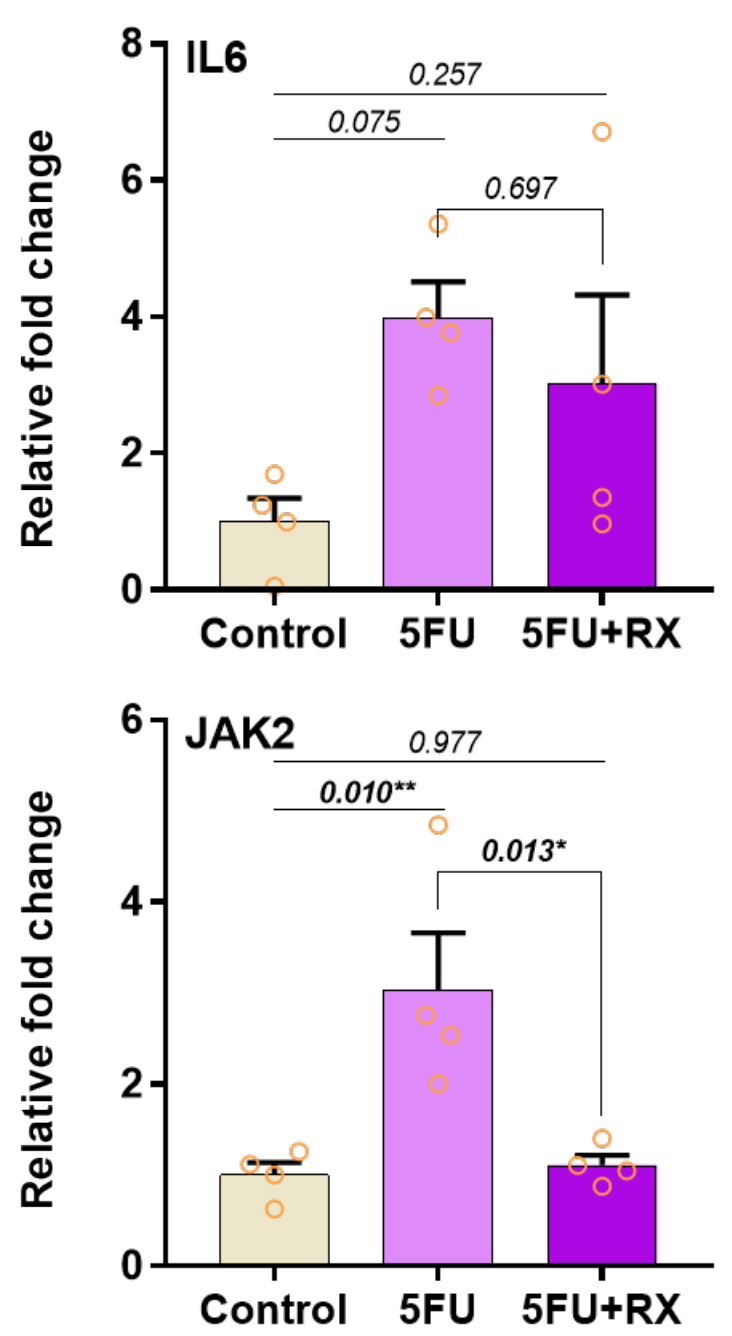
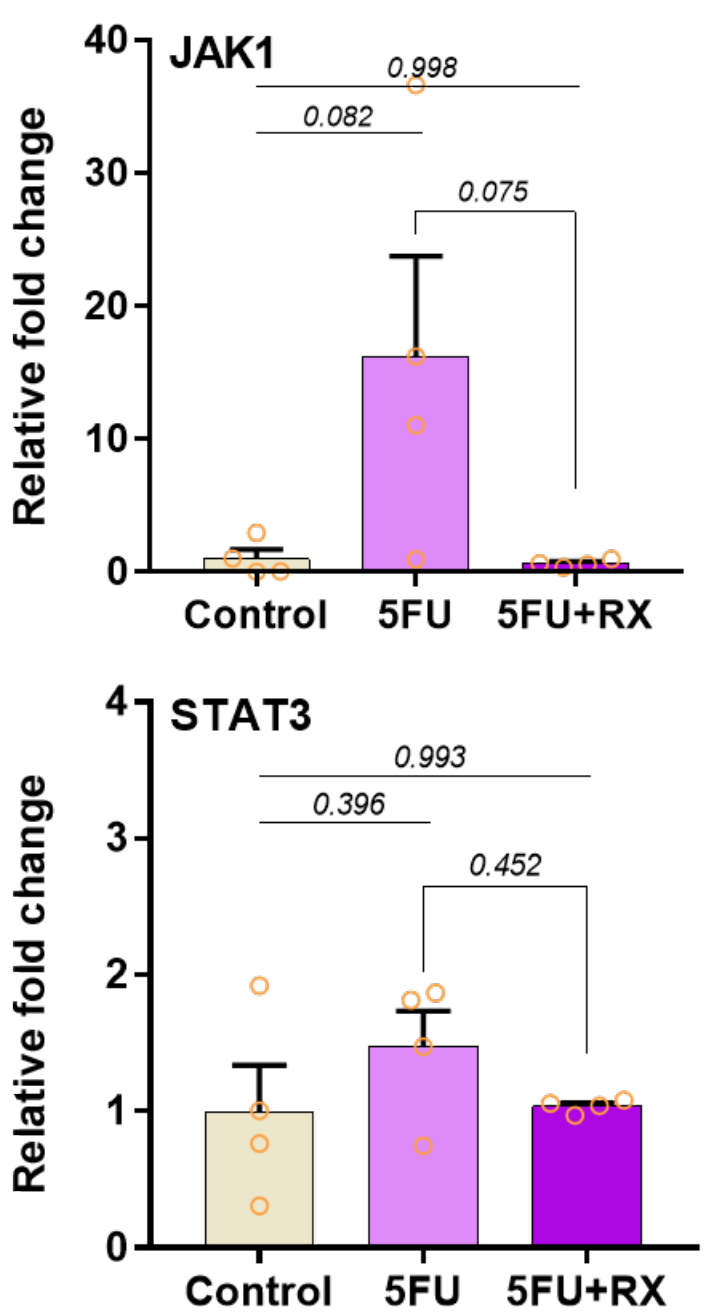

Figure 4: Relative fold change qRT-PCR analysis of IL-6, JAK1, JAK2, and STAT3 genes in IC50 doses of 5-FU and 5-FU+Ruxo exposed U87 cell line. (All data were normalized with $\beta$-actin expression and given as relative to control (control $=1)$. Values expressed as mean \pm standard error $(n=4) .{ }^{*}$ Indicates significantly different values, one-way ANOVA, Tukey HSD test : $p \leq 0.05,{ }^{* *} p \leq 0.01$.)

Changes in caspase 3 and caspase 8 expressions were found statistically insignificant in U87 cells treated with a combination of 5-FU+Ruxo. However, the apoptotic effect of 5-FU alone is more pronounced than the apoptotic effect of the 5-FU+Ruxo combination. Acridine orange stains both living and dead cells, while ethidium bromide stains only membrane-lost cells. Therefore, while living cells are stained equally green, early apoptotic cells have bright green punctuation in the nucleus due to nuclear fragmentation. However, late apoptotic cells are stained orange with ethidium bromide (15). In our study, only 5-FU treated cells were stained bright green, while 5-FU+Ruxo treated cells were mostly stained bright orange. Both fluorescence staining and gene expression results showed that apoptosis induced in the glioblastoma cell line.

In our study, it was found that 5-FU+Ruxo administration suppressed JAK1 and JAK2 expression compared to 5-FU application (Figure 4). However, only the difference in JAK2 was statistically significant. The Janus kinase/signal transducers and activators of transcription (JAK/STAT) pathway is the principal signaling for immune response, growth factor or cytokine regulation, cell proliferation, differentiation, cell mi- 
gration as well as autophagy and apoptosis $(16,17)$. JAK/STAT pathway also plays a critical role in the rapid transduction of signals from the cell surface to the nucleus $(18,19)$. Pro-inflammatory cytokine IL-6 signals through IL6-R-gp130/JAK1 and JAK2 complexes, resulting in the downstream phosphorylation of STAT3 and/or STAT5 (homo or heterodimers). These STAT complexes translocate nucleus and trigger a wide array of genes involved in processes ranging from cell survival or proliferation to inflammation. The phosphorylated sites on the IL6-receptor and JAKs serve as docking sites for the SH2-containing STAT3, and for SH2-containing proteins and adaptors that link the receptor to MAP kinase, PI3K/AKT/mTOR. Therefore, the IL6 / gp130 receptor complex is important in ensuring cell viability (20-22). In light of these findings, it is thought that the strong decrease in cell proliferation seen in MTT test and microscope images in ruxo treatment groups is due to the inhibition of cell proliferation due to JAK signal activated by 5 -FU.

The limitations of our study are that we used only four replicates for control, and treatment groups and applied agents to a single cell line. However, we think that our data do reflect some potential clinical scenarios in GBM patients, especially patients who experienced exposure to both 5-FU and Ruxo. However, it is necessary to validate the results with studies using more repetition and types of cell lines as well as in vivo models.

In conclusion, this study is, to the best of our knowledge, the first to investigate the combined effect of 5-FU and Ruxo on the glioblastoma cell line. Additionally, our findings indicate that $5-\mathrm{FU}$ alone or combined with Ruxo caused inhibition of cell proliferation of U87 glioblastoma cells via triggering mitochondrial apoptosis. While these initial results are important for the usability of 5-FU and Ruxo in glioblastoma, further detailed studies are needed.

\section{Ethics Committee Approval: N/A \\ Informed Consent: N/A \\ Conflict of Interest: The authors declared no conflict of interest. Author contributions: Concept: GA, OD, ZBD, Supervision: OD, ZBD, Resources: GA, OD, ZBD, Materials: GA, OD, ZBD, Data collection and/or processing: GA, OD, ZBD, Analysis and/or Interpretation: GA, OD, ZBD, Literature Search: GA, OD, ZBD, Writing Manuscript: GA, OD, ZBD, Critical Review: GA, OD, ZBD.}

Financial disclosure: The authors declared that this study received no financial support.

\section{REFERENCES}

1. Bedini A, Baiula M, Vincelli G et al. Nociceptin/orphanin FQ antagonizes lipopolysaccharide-stimulated proliferation, migration and inflammatory signaling in human glioblastoma U87 cells. Biochem Pharmaol 2017;140:89-104.

2. Batash R, Asna N, Schaffer P et al. Glioblastoma multiforme, diagnosis and treatment; recent literature review. Curr Med Chem 2017;24(27):3002-9.

3. Alifieris C, Trafalis DT. Glioblastoma multiforme: pathogenesis and treatment. Pharmacol Ther 2015;152:63-82.

4. Leelakanok N, Geary S, Salem A. Fabrication and use of poly(d,1lactide-co-glycolide)-based formulations designed for modified release of 5-Fluorouracil. J Pharm Sci 2018;107(2):513-28

5. Diasio RB, Harris BE. Clinical pharmacology of 5-Fluorouracil. Clin Pharmacokinet 1989;16(4):215-37.

6. Akca H, Ozes ON. Antitumor effects of TNF- $\beta$, 5-FU and their combinations on cervical carcinoma cell lines. 2002;32:127-32.

7. Goker Bagca B, Avci CB. Ruxolitinib and effect mechanism. FNG \& Demiroğlu Bilim Tip Dergisi 2016;2(2):153-7.

8. LiverTox: Clinical and Research Information on Drug-Induced Liver Injury [Internet]. Bethesda (MD): National Institute of Diabetes and Digestive and Kidney Diseases; 2012. Ruxolitinib. (Updated 2018 Jun 4). Available from: URL: https://www.ncbi.nlm.nih. gov/books/NBK548534/pdf/Bookshelf_NBK548534.pdf.

9. Delen E, Doganlar O, Doganlar ZB et al. Inhibition of the invasion of human glioblastoma U87 cell line by ruxolitinib: a molecular player of miR-17 and miR-20a regulating JAK/STAT pathway. Turk Neurosurg 2020;30(2):182-9.

10. Xu J, JiL D, Xu LH. Lead-induced apoptosis in PC 12 cells: Involvement of $\mathrm{p} 53, \mathrm{Bcl}-2$ family and caspase-3. Toxicol Lett 2006;166(2):160-7.

11. Erdogan MK, Agca CA, Askin H. Enhanced antiproliferative and apoptotic effects of 5-fluorouracil by combined with Pistacia eurycarpa extracts on human colorectal cancer cells. BioDiCon 2019;12(1):27-38.

12. Winter RN, Kramer A, Borkowski A et al. Loss of caspase-1 and caspase- 3 protein expression in human prostate cancer. Cancer Res 2001;61(3):1227-32.

13. Teitz T, Wei T, Valentine MB et al. Caspase 8 is deleted or silenced preferentially in childhood neuroblastomas with amplification of MYCN. Nat Med 2000;6(5):529-35.

14. Shivapurkar N, Toyooka S, Eby MT, et al. Differential inactivation of caspase- 8 in lung cancers. Cancer Biol Ther 2002;1(1):65-9. 15. Kasibhatla, S. Acridine Orange/Ethidium Bromide (AO/EB) Staining to Detect Apoptosis. Cold Spring Harbor Protocols, 2006 (21). doi:10.1101/pdb.prot4493

16. Jatiani SS, Baker SJ, Silverman LR et al. Jak/STAT pathways in cytokine signaling and myeloproliferative disorders: approaches for targeted therapies. Genes Cancer 2010;1(10):979-93.

17. Owen KL, Brockwell NK, Parker BS. JAK-STAT signaling: a double-edged sword of immune regulation and cancer progression. Cancers (Basel) 2019;11(12):2002.

18. Imada K, Leonard WJ. The JAK-STAT pathway. Molecular Immunology 2000;37:1-11.

19. Schindler C, Levy DE, Decker T. JAK-STAT signaling: from interferons to cytokines. Journal of Biological Chemistry 2007;282(28):20059-63. 
20. Masjedi A, Hashemi V, Hojjat-Farsangi M et al. The significant role of interleukin-6 and its signaling pathway in the immunopathogenesis and treatment of breast cancer. Biomedicine \& Pharmacotherapy 2018;108:1415-24.

21. Rose-John S. IL-6 trans-signaling via the soluble IL-6 receptor: importance for the pro-inflammatory activities of IL-6. Int J Biol Sci 2012;8(9):1237-47.

22. Yu H, Lee H, Herrmann A et al. Revisiting STAT3 signalling in cancer: new and unexpected biological functions. Nat Rev Cancer 2014;14(11):736-46. 